\title{
Did You Say: Chemical, Process and Product-Oriented Engineering?
}

\author{
J.C. Charpentier ${ }^{1 *}$ \\ 1 Department of Chemical Engineering / CNRS, École supérieure de chimie physique électronique de Lyon, \\ 43, boulevard du 11 Novembre 1918, BP 2077, 69616 Villeurbanne Cedex - France \\ e-mail: charpentier@cpe.fr \\ * Scientific chairman of the French Society of Chemical Engineering
}

\begin{abstract}
Résumé - Vous avez dit : Génie chimique, génie des procédés, génie orienté produit ? - Si hier, l'industrie était reine, aujourd'hui, le client est roi. En l'an 2000, pour adapter l'approche Génie chimique aux besoins des industries des procédés et répondre à la demande des marchés, l'offre est technologique. L'évolution du génie chimique, facteur clé de la survie au cœur des marchés mondiaux, qui inclut besoins et défis, est examinée; sa capacité à affronter les problèmes rencontrés par les industries chimiques et parachimiques est évaluée. Il apparaît que les progrès nécessaires se feront via une approche multidisciplinaire et multiéchelle (de temps et d'espace) qui devra satisfaire à la fois les contraintes du marché relatives aux propriétés d'usage des produits et les contraintes environnementales et sociétales des procédés industriels. Ces progrès seront réalisés grâce aux percées de la modélisation moléculaire et de l'instrumentation scientifique, et grâce à la puissance des moyens de calcul. Il en découle quatre défis essentiels pour les ingénieurs et les chercheurs :

- augmenter la productivité et la sélectivité des procédés grâce à une conduite intelligente, à un contrôle avancé multiéchelle;

- concevoir de nouveaux équipements basés sur des principes scientifiques et de nouveaux modes de production;

- étendre la méthodologie du génie chimique au génie orienté produit, i.e. les propriétés d'usage du produit final : le génie du triplé « processus-produit-procédé »;

- étendre les applications multiéchelles de la modélisation et de la simulation aux situations réelles : de l'échelle de la molécule à celle du produit global sophistiqué.
\end{abstract}

Mots-clés : avenir du génie des procédés, approche multidisciplinaire et multiéchelle, génie du triplé «processus-produit-procédé », propriétés d'usage, matière molle, acquisition de données de base, modélisation moléculaire, nouveaux types de procédés.

\footnotetext{
Abstract_Did You Say: Chemical, Process and Product-Oriented Engineering? - Industry used to be king, now the customer is. In year 2000, to adapt the chemical engineering approach to the needs of process industries and meet market demands, the offer is technological.

Being a key to survival in global markets, including needs and challenges, the evolution of chemical engineering is received and its ability to cope with the problems encountered by chemical and related process industries is appraised. It appears that the necessary progress will come via a multidisciplinary and time and length multiscale approach that will allow us to satisfy both the markets requirements for specific end-use properties and the environmental and social constraints of the industrial processes. This
} 
will be obtained with breakthroughs in molecular modeling, scientific instrumentation and powerful computational tools. This concerns four main objectives for engineers and researchers:

- to increase productivity and selectivity through intelligent operation, intensification and multiscale control of processes;

- to design novel equipment based on scientific principles and new methods of production;

- to extend chemical engineering methodology to product-oriented engineering, i.e. manufacturing enduse properties: the triplet "process-product-procedure",

- to implement multiscale application of computational chemical engineering modeling and simulation to real-life situations: from the molecule scale to the overall complex product scale.

Keywords: future of chemical engineering, multidisciplinary and multiscale approach, triplet "process-product-procedure" engineering, end-use property, soft solids, data bank acquisition, molecular modeling, new types of processes.

\section{PROBLEMS AND CHALLENGES ENCOUNTERED BY CHEMICAL AND RELATED INDUSTRIES}

The world is moving forward. For developing and industrializing countries there is a low cost of manpower and less constraining local production regulations. For industrialized countries, there is a rapid development in consumer demand and constraints stemming from public concern over environment and safety issues.

In response to these changes, and in competition with US and Japanese industries, the petroleum, petrochemical, chemical and other related European industries are confronted with a double challenge from a technological and scientific point of view:

- to research innovative processes for the production of commodity and intermediate products, no longer selecting processes on the basis of economic exploitation alone but seeking compensatory gains resulting from the increased selectivity and savings linked to the process itself. This requires valorization of safety, health and environmental aspects, including the value of nonpolluting technologies, reduction of raw material and energy losses and product and by-product recyclability as well. The customer will buy a process which is nonpolluting, defect-free and perfectly safe;

- to progress from traditional intermediate chemistry to new specialities and active material chemistry and parachemistry. This includes upgrading and conversion of petroleum feedstocks and intermediates, conversion of coal-derived chemicals or synthesis gas into fuels, hydrocarbons or oxygenates, along with the chemistry/ biology interface, i.e. the postgenomic world. This aim is characterized by new market objectives, with sales and competitiveness dominated by the value of use or the end-use properties (size, shape, color, touch, handling, cohesion, friability, rugosity, taste, succulence, esthetics, sensory properties, magnetics, etc.). Expertise in designing process adjustments to variety and changing demand along with speed in reacting to market conditions will be the dominant elements. The client will buy the product which is the most efficient and the first on the market, thus strengthening the existing competition between developed country producers.

\section{CHEMICAL AND PROCESS ENGINEERING}

Chemical and process engineering must help meet these challenges. The objective of chemical engineering is the synthesis, design, scale-up or scale-down, operation, control and optimization of industrial processes that change the state, microstructure and chemical composition of a material through physicochemical separations (distillation, absorption, liquid-liquid extraction, filtration, precipitation, permeation, adsorption, ion-exchange, fluidization, emulsification, crystallization, etc.) as well as through chemical, catalytic, biochemical, electrochemical, photochemical and agrochemical reactions. Chemical engineering thus covers areas involving a wide variety of technologies, such as those in the oil, metallurgy, chemical, pharmaceutical, cosmetics, pulp, concrete and glass industries as well as in the advanced and emerging technologies, such as biotechnology, microelectronics, nanotechnologies, new materials, and process control and safety, with increasing emphasis on the demand of end-use properties.

It is important to note that today $60 \%$ of all products that a chemical company sells to its customers are crystalline, polymeric or amorphous solids. These products need to have a clearly defined physical shape in order to meet the desired quality standards. This also applies to paste-like and emulsified products. Instead of classical basic and industrial chemicals, new developments increasingly concern highly targeted and specialized materials, active compounds and special effect chemicals. These are much more complex in terms of molecular structure than classical chemicals.

Although the purpose of basic research in chemical and process engineering is still the development of concepts, methods and techniques to better understand, conceive and design processes to change raw materials and energy into useful products, the complexity of the phenomena involved in industrial processes now increasingly forces the engineer and researcher to develop new concepts and methods. This 


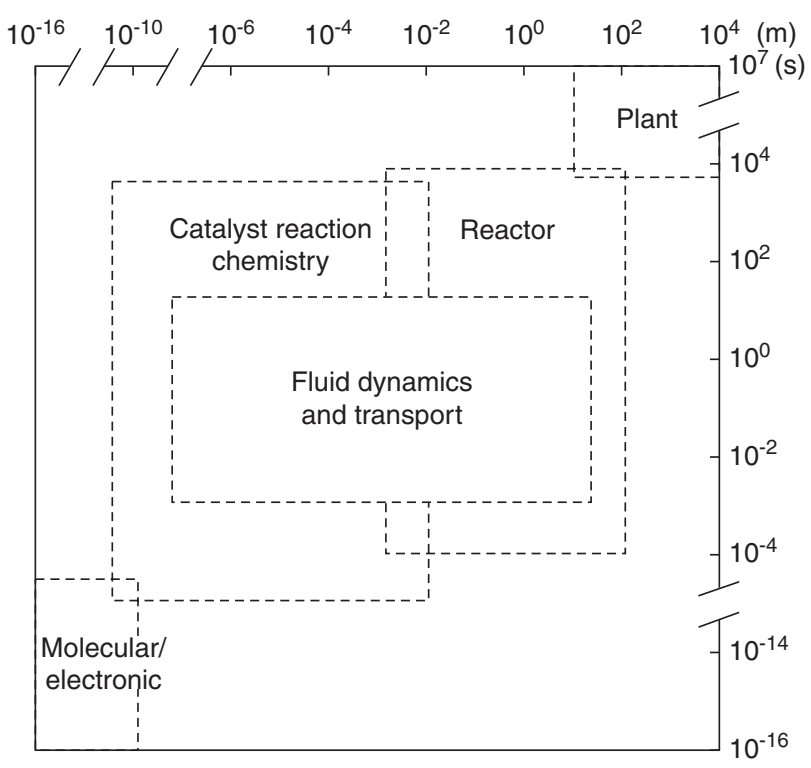

Figure 1

The length and time scales covered in the multiscale approach.

necessitates an integrated system approach for simultaneous and often coupled phenomena and processes taking place on different scales (Fig. 1):

- different time scales $\left(10^{-15}-10^{8} \mathrm{~s}\right)$, from femto and picoseconds for the motion of atoms in a molecule during a chemical reaction, nanoseconds for molecular vibrations, to the scale of hours for operating industrial processes and centuries for the destruction of pollutants in the environment;

- different length scales $\left(10^{-8}-10^{6} \mathrm{~m}\right)$ in industrial practice with approaches on the nanoscale (molecular processes, active sites), on the microscale (particles, droplets, bubbles, eddies), on the mesoscale (reactors, exchangers, separators, pumps), on the macroscale (production units, plants) and lastly on the megascale (environment, atmosphere, oceans, soils) (Figure 2 for chemical considerations, Figure 3 for biochemical considerations and Figure 4 for applications in polymer reaction engineering). It will be possible to understand and describe the relationship between events on the nanoscale and microscale to better convert molecules into useful products on the process scale thanks to significant breakthroughs in:

- molecular modeling (both theory and computer simulations);

- scientific instrumentation and noninvasive measurement techniques (nuclear magnetic resonance, temporal analysis of product, impedance tomography, spectroscopic or monochromatic, ellipsometry, etc.) and related nanotechnologies in connection with image processing (particle image velocimetry, laser doppler anemometry, laser-induced fluorescence, computed-automated radioactive particle tracking, computed tomography);

- powerful computational tools and capabilities (Fig. 5).

This explains why, in addition to the basic notions of unit operations and coupled transfers, new concepts are now found for process engineering together with chemical engineering concepts to analyze, design and operate processes to get a product (often having a short life cycle) first on the market, optimally and with the desired properties by means of processes with zero defects, zero pollution and zero accidents.

It should be emphasized that product quality is determined at the micro and nano level and that a product with a desired property must be investigated for both structure and function. This involves a thorough understanding of the structure/ property relationship at both molecular (e.g. surface physics

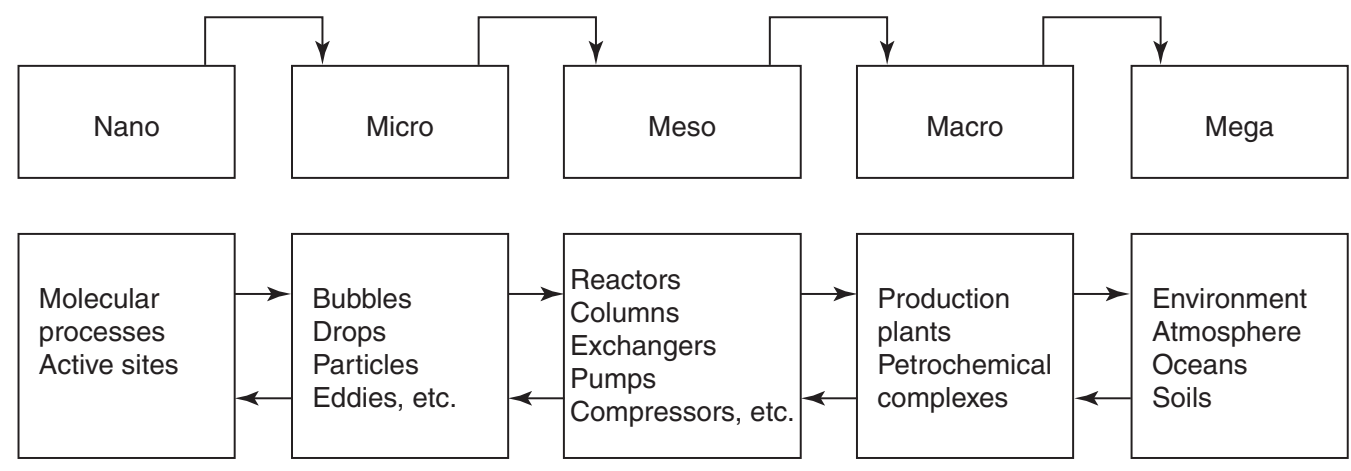

Figure 2

Scales and complexity levels in process engineering: to understand and to describe the relationships between events on nano- and microscale to better convert molecules into useful products on the process scale. 


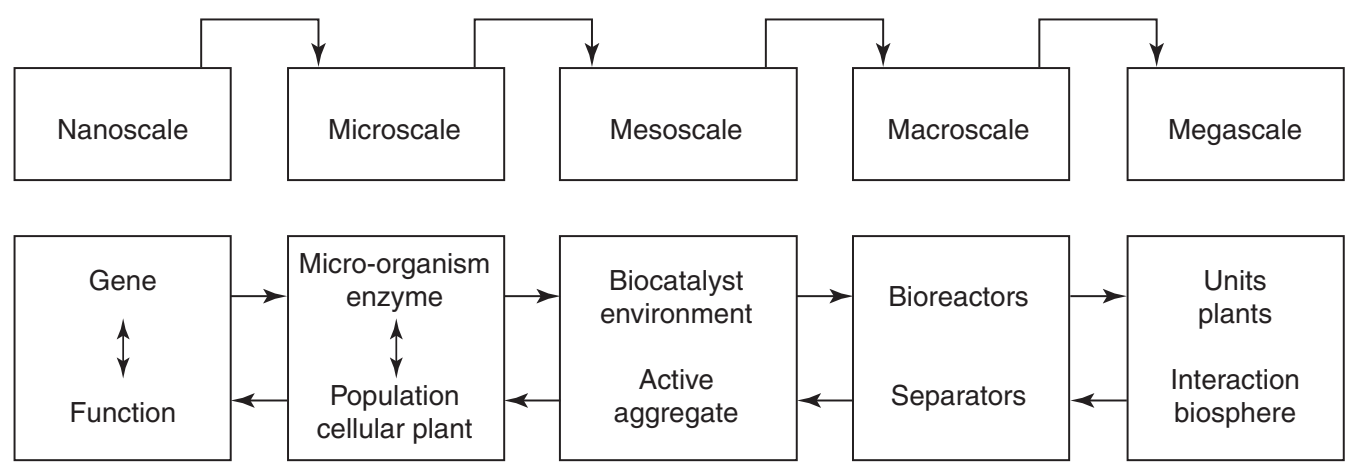

Figure 3

Biochemistry and biochemical engineering: from the gene with known structure and function to the end-use property (or function) product (ecoproduct). Organizing levels of complexity underlie new view of biochemical engineering with an integrated approach of phenomena and simultaneous and coupled processes.

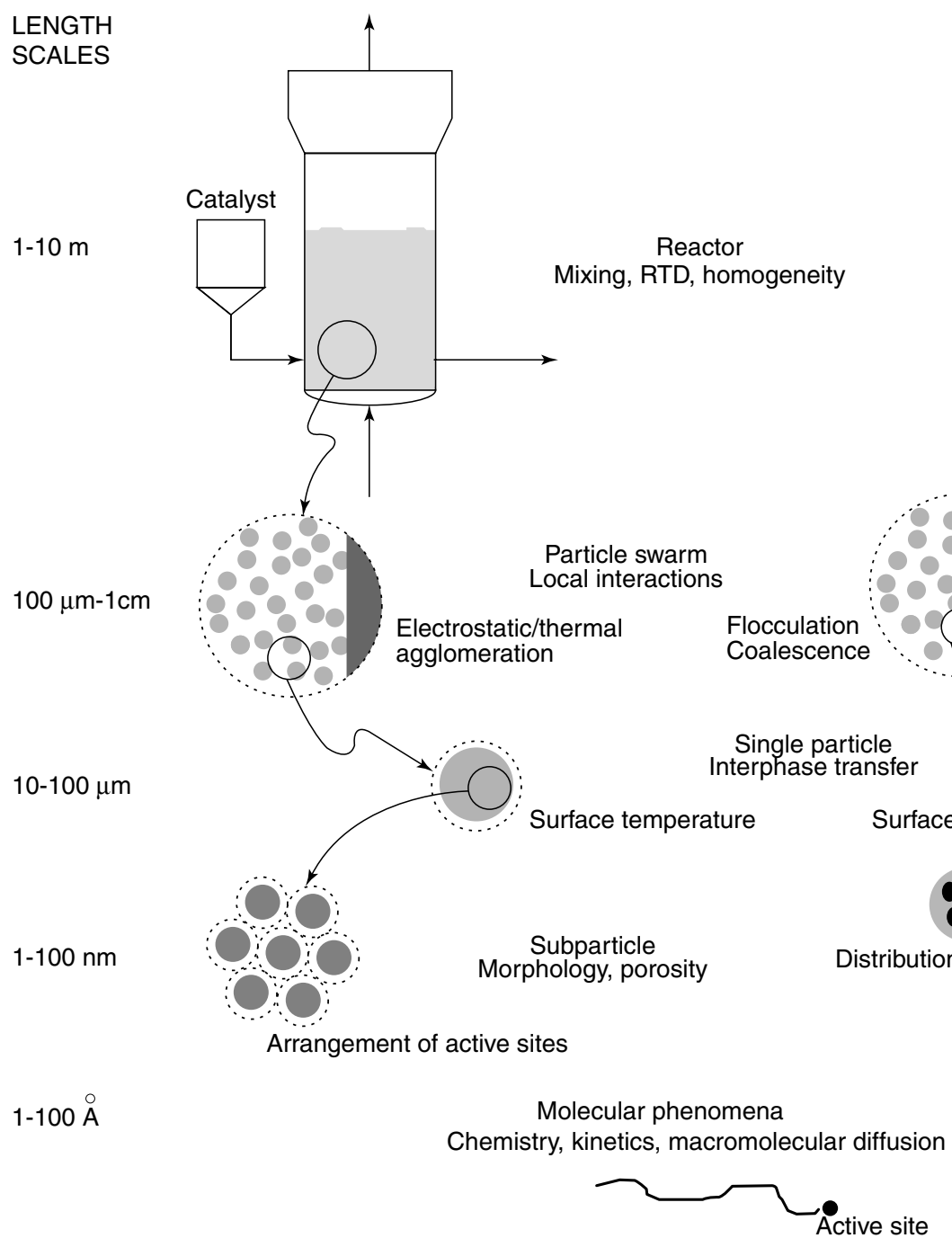

Figure 4

Length scales involved in polymer reaction engineering. 


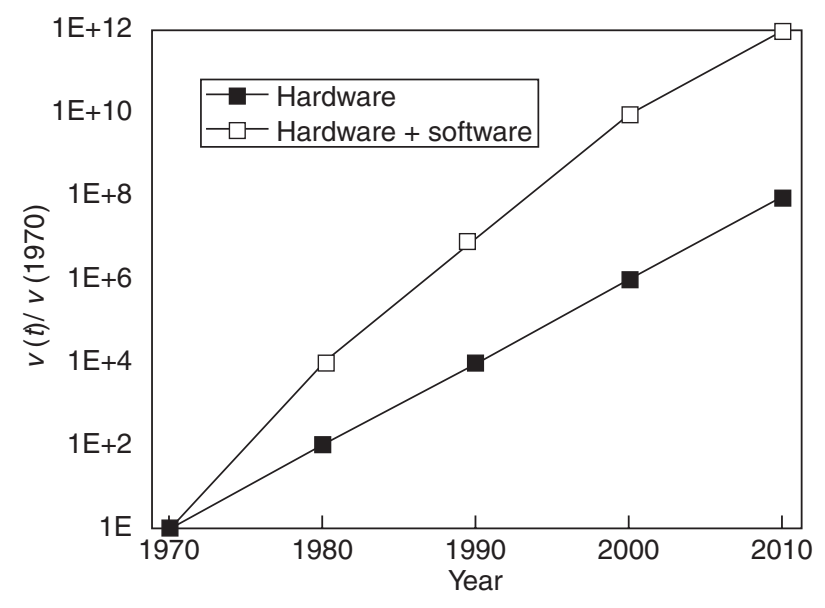

Figure 5

Computing speed acceleration.

and chemistry) and microscopic levels. The ability to control microstructure formation to obtain the right end-use properties of a fluid or solid product is the key to success and will help design and control product quality and make the leap from the nano level to the process level.

\section{CHEMICAL, PROCESS AND PRODUCT-ORIENTED ENGINEERING}

The future in chemical engineering involves multidisciplinary collaboration among physicists, chemists, biologists, mathematicians and instrumentation specialists, leading to theoretical development of the product and formulation engineering, i.e. the design of products with complex structures (emulsions, paste-like products, plastics, ceramics, soft products and solids). Developing new concepts adapted to this idea of the product, within the framework of what could be called "physicochemical (bio) engineering" justifies the qualification of process engineering as an extension of chemical engineering and takes on its full meaning.

Improving both the design and evaluation of complex systems for the production of real products requires further research into methodologies, tools and strategies. These should be orientated toward the acquisition of basic data in thermodynamics, kinetics, rheology and transport, and toward the conception of new integrated operations allowing for coupling and uncoupling of elementary processes (transfer, reaction, separation) or combining several functions in one piece of equipment (as is the case in reactive distillation, crystallization or reactive membrane separation). This will clear the way to smaller and cheaper installations requiring improved knowledge in process modeling, automation and control.
Moreover, chemical, petrochemical and parachemical processes and product engineering have a great need for mathematical models and useful data to be processed with powerful computational tools. For example, computational fluid dynamics, due to the recent rapid advances in available software (e.g. FLUENT, PHOENICS, FLOW 3D, FIDAP, FLOW MAP, etc.) is daily becoming more important in scaling up new equipment or multifunctional unit operations by simulation of flow phenomena and processing generalized local information, i.e. for understanding the impact of complex flow geometries on mixing and reaction phenomena on the microeddy scale or for numerical simulation of the complex hydrodynamics of multiphase gas-liquid-solid reactors. The increasing power of computers also plays a decisive role in image and signal processing for visualization and validation, particularly applied to real media (particulate or opaque).

In summary, the previous considerations on the future of chemical engineering involving process and product engineering (what we call in French le génie du triplé processus-produit-procédé) concern four main objectives for engineers and researchers:

- to increase productivity and selectivity through intelligent operation and multiscale control of processes: this leads to the intensification of processes, needs the use of micro- and nanotechnology and necessitates a transfer of information between man and process (in both directions) which involves mathematical models, arrays of local sensors, close computer control and fine image and signal processing for visualization and validation;

- to design novel equipment based on scientific principles and new methods of production: multifunctional reactors, new operating modes, miniaturization, modularization and decentralization for production modes;

- to extend chemical engineering methodology to productoriented engineering, i.e. manufacturing end-use properties with the construction of sophisticated products combining several functions and properties: detergents, lubricants, surfactants, plastics, foods, pharmaceuticals, cosmetics, agrochemicals, petrochemicals and more. This corresponds to an ever-growing market demand and the end-use property has to be built and scaled up from nanoor microscale liquid or solid structures that meet consumer demands on the product mesoscale. In practice, this mostly concerns complex media and particulate solids;

- to implement multiscale application of computational chemical engineering modeling and simulation to real-life situations: from the molecule to the overall complex product scale, i.e. molecular modeling based on information from data banks to calculate vapor-liquid equilibria, adsorption on surfaces, polymer properties, microporous materials or ceramic structure; from the laboratory scale or mock-up scale to macroscopic industrial reactors with multilevel modeling of continuous and dispersed 
multiphase flows; and modeling on the scale of the whole plant to optimally structure the production complex by dynamic process simulation and tools and techniques for diagnosing and solving operating problems including reactor safety, runaway prevention and control.

\section{WHAT ABOUT THE FUTURE? OBJECTIVE 2010}

Oral presentations and discussions at the present Rencontres scientifiques de l'IFP, entitled "Chemical Reactors, from Mock-up to Industrial Reactor: Diagnostic Methods", with a special emphasis on modeling methods and tools in multiphase reactors, showed up-to-date illustrations of the previous considerations, and especially focussed on diagnostic methods for scaling up chemical reactors from meso(mock-up) to macroscale (industrial reactor).

For instance in the final round table panel, three items were thoroughly discussed:

- the state of knowledge about the present tools and their development and potentiality in the next decade: this will be linked to the development of scientific instrumentation, noninvasive measurement techniques and related technologies in connection with signal and image processing;

- scaling-up (or down), a perennial problem in multiphase reactors, and methodology and experimental means in the present and future contexts involving more and more severe quality and selectivity requirements. As mentioned previously product quality is determined at the micro and nano level which requires prior modeling (i.e. molecular modeling) to predict the quality at the mock-up level. As a result, further developments are needed and expected in the improved description of fundamental chemical and physical processes, particularly necessary to model reaction systems;

- the specifics and future challenges to get a better analysis of the behavior of any size reactor and achieve rapid optimization of units, which is essential for success. Participants felt that computational fluid dynamics (CFD) and computational fluid mixing (CFM) would take an ever greater importance in near future, in some cases making pilot unit experiments (and sometimes mock-up experiments!) unnecessary, especially if the interaction of kinetics and fluid dynamics is taken into account.

Lastly, it should not be forgotten that engineers and scientists in chemical, process and product-oriented engineering are problem solvers requiring a precise diagnostic, a clear understanding of the process on all time and length scales and rapid optimization, and that this necessitates experiments, modeling and simulation.

Final manuscript received in February 2000 